\title{
Pressure-induced decoupling of the order-disorder and displacive contributions to the phase transition in diguanidinium tetrachlorostannate
}

\author{
Szafranski, M.; Ståhl, Kenny
}

Published in:

Physical Review B Condensed Matter

Link to article, DOI:

10.1103/PhysRevB.62.8787

Publication date:

2000

Document Version

Publisher's PDF, also known as Version of record

Link back to DTU Orbit

Citation (APA):

Szafranski, M., \& Ståhl, K. (2000). Pressure-induced decoupling of the order-disorder and displacive contributions to the phase transition in diguanidinium tetrachlorostannate. Physical Review B Condensed Matter, 62(13), 8787-8793. https://doi.org/10.1103/PhysRevB.62.8787

\section{General rights}

Copyright and moral rights for the publications made accessible in the public portal are retained by the authors and/or other copyright owners and it is a condition of accessing publications that users recognise and abide by the legal requirements associated with these rights.

- Users may download and print one copy of any publication from the public portal for the purpose of private study or research.

- You may not further distribute the material or use it for any profit-making activity or commercial gain

- You may freely distribute the URL identifying the publication in the public portal 


\title{
Pressure-induced decoupling of the order-disorder and displacive contributions to the phase transition in diguanidinium tetrachlorostannate
}

\author{
Marek Szafrański \\ Institute of Physics, Adam Mickiewicz University, Umultowska 85, 61-614 Poznań, Poland \\ Kenny Ståhl \\ Department of Chemistry, Technical University of Denmark, DK-2800 Lyngby, Denmark
}

(Received 15 February 2000)

\begin{abstract}
The crystals of diguanidinium tetrachlorostannate $\left[\mathrm{C}\left(\mathrm{NH}_{2}\right)_{3}\right]_{2}^{+} \cdot \mathrm{SnCl}_{4}^{-2}$, were studied by single-crystal $\mathrm{x}$-ray diffraction at various temperatures and by calorimetric and dielectric measurements at ambient and high hydrostatic pressures. At room temperature the crystal structure is orthorhombic, space group $\mathrm{Pbca}$, and consists of infinite staggered $\left(\mathrm{SnCl}_{4}^{-2}\right)_{n}$ chains built of square pyramids sharing corners and of two crystallographically different guanidinium cations $G(1)$ and $G(2)$, located in two kinds of voids between the chains. The polyanionic chains are tied into double sheets by the $G(1)$ cations. At ambient pressure the crystals undergo two first-order phase transitions at 354.8 and $395.4 \mathrm{~K}$. The former, between two orthorhombic phases $(\mathrm{Pbca} \rightarrow \mathrm{Cmca}$ ), is characterized by antiphase displacement of the double sheets along the $b$ direction of the low-temperature unit cell which is coupled to dynamical disordering of $G(2)$ and transformation of its hydrogen bonding scheme. At elevated pressures the coupling between the displacive and order-disorder contributions is modified and its breaking near a triple point at $180 \mathrm{MPa}$ and $270 \mathrm{~K}$ results in a pressure-induced phase observed between $\mathrm{Pbca}$ and $\mathrm{Cmca}$ phases.
\end{abstract}

\section{INTRODUCTION}

Among the compounds based on organic cations and halogenometallate anions an interesting group of crystals are those of the general formula $A_{2} M X_{4}$, where $A$ is an organic monocation, $M$ a divalent metal, and $X$ a halogen. Their studies have been stimulated by a variety of structural phase transitions associated with ferroelectric, ferroelastic, magnetic and other properties. ${ }^{1}$ Of particular interest are the structures with the low-dimensional anionic sublattice patterns. Such crystals usually exhibit a strong anisotropy of properties and are relatively highly susceptible to thermodynamic factors. Temperature or pressure can disturb the balance between the ions and layers leading to structural transformations. The phase transitions in the most abundant halogenometallates containing chainlike cations can in most cases be ascribed to conformational or configurational disordering of the cations (see, for example, Ref. 2, and references cited therein), or rotational distortions of anionic sublattices. ${ }^{3,4}$ Recently we synthesized new halogenometallates ${ }^{5-7}$ with guanidinium cation $\left[\mathrm{C}\left(\mathrm{NH}_{2}\right)_{3}\right]^{+}$, which is an essentially planar unit in solids. The studies of guanidinium halogenoplumbates ${ }^{7-9}$ revealed a series of transformable crystals including the crystal belonging to the $A_{2} M X_{4}$ family, diguanidinium tetraiodoplumbate $\left[\mathrm{C}\left(\mathrm{NH}_{2}\right)_{3}\right]_{2}^{+} \cdot \mathrm{PbI}_{4}^{-2}$. The latter is especially noteworthy owing to the unique behavior under hydrostatic pressure including a pressure-induced disordering of the cations and the critical point ending the line of isostructural phase transitions. ${ }^{9}$ A further extension of these materials are guanidinium halogenostannates. In this paper we describe the structure and properties of diguanidinium tetrachlorostannate $\left[\mathrm{C}\left(\mathrm{NH}_{2}\right)_{3}\right]_{2}^{+} \cdot \mathrm{SnCl}_{4}^{-2}$ (hereafter $\left.\mathrm{G}_{2} \mathrm{SnCl}_{4}\right)$. The crystal has been characterized by calorimetric and dielectric measurements at ambient and high hydrostatic pressures as well as by $\mathrm{x}$-ray diffraction at various temperatures. The structure and its temperature evolution is described with reference to the microscopic mechanism of the phase transitions observed in this material. We also indicate and discuss an unusual effect of pressure on the transition mechanism.

\section{EXPERIMENT}

The crystals were grown by slow evaporation from the saturated aqueous solution of guanidinium chloride and stannous chloride. An excess of guanidinium chloride had to be added to the stoichiometric solution because otherwise the $\left[\mathrm{C}\left(\mathrm{NH}_{2}\right)_{3}\right]^{+} \cdot \mathrm{SnCl}_{3}^{-}$compound was formed, as a rule. The $\mathrm{G}_{2} \mathrm{SnCl}_{4}$ crystals crystallized in the form of needlelike pseudohexagonal or triangular prisms, very often twinned and bent.

Calorimetric measurements were performed by differential thermal analysis (DTA) in the temperature range from 120 to $420 \mathrm{~K}$. The polycrystalline samples of about $50 \mathrm{mg}$ were heated/cooled at a temperature rate ranging from 1 to 5 $\mathrm{K} / \mathrm{min}$. Pure indium was used for calibration of the calorimeter. The transition enthalpies and entropies were determined with an accuracy of $10 \%$ as mean values of several DTA measurements. The transition temperatures were obtained on the basis of several runs at different temperature rates and then by extrapolation to $0 \mathrm{~K} / \mathrm{min}$.

The influence of high pressure on the $\mathrm{G}_{2} \mathrm{SnCl}_{4}$ crystal structure was studied by the high-pressure DTA (Ref. 10) and dielectric methods. The measurements were performed under pressures from 0.1 to $700 \mathrm{MPa}$ in the temperature range between 120 and $380 \mathrm{~K}$. A beryllium-copper cell with helium or nitrogen gas as a pressure transmitting medium 
TABLE I. Data collection, data reduction and refinement information for $\mathrm{G}_{2} \mathrm{SnCl}_{4}$ at $293 \mathrm{~K}$ and $360 \mathrm{~K}$.

\begin{tabular}{|c|c|c|}
\hline Temperature (K) & 293(2) & $360(1)$ \\
\hline Crystal dimension (mm) & $0.4 \times 0.02 \times 0.01$ & $0.5 \times 0.1 \times 0.07$ \\
\hline Chemical formula & \multicolumn{2}{|c|}{$\left[\mathrm{C}\left(\mathrm{NH}_{2}\right)_{3}\right]_{2}^{+} \cdot \mathrm{SnCl}_{4}^{2-}$} \\
\hline $\mathrm{Z}$ & \multicolumn{2}{|c|}{8} \\
\hline Space group & Pbca & Cmca \\
\hline Unit cell $a(\AA)$ & $10.1518(2)$ & $8.049(2)$ \\
\hline$b(\AA)$ & $8.0972(1)$ & $30.845(6)$ \\
\hline$c(\AA)$ & $31.2036(2)$ & $10.247(2)$ \\
\hline$V\left(\AA^{3}\right)$ & $2565.0(1)$ & $2544.0(9)$ \\
\hline Density $\left(\mathrm{gcm}^{-3}\right)$ & 1.97 & 1.99 \\
\hline Abs. coeff. $\left(\mathrm{mm}^{-1}\right)$ & 2.80 & 2.82 \\
\hline Wavelength ( $\mathrm{\AA})$ & \multicolumn{2}{|c|}{0.71073} \\
\hline \multicolumn{3}{|l|}{ No. of reflections } \\
\hline collected/unique $/ I>2 \sigma_{I}$ & $24997 / 3790 / 2010$ & $2100 / 593 / 322$ \\
\hline$R_{\text {int }}(\%)$ & 10 & 20 \\
\hline No. of parameters/restrains & $178 / 14$ & $78 / 0$ \\
\hline Maximum $\sin \Theta / \lambda \quad\left(\AA^{-1}\right)$ & 0.723 & 0.596 \\
\hline$R(F)$, all $/ I>2 \sigma_{I}(\%)$ & $16.2 / 7.4$ & $13.5 / 5.6$ \\
\hline$w R\left(F^{2}\right)$, all $/ I>2 \sigma_{I}(\%)$ & $9.9 / 8.4$ & $17.7 / 13.3$ \\
\hline GOF & 1.25 & 1.06 \\
\hline
\end{tabular}

was placed in a thermal bath of controlled temperature. Pressure was measured by a manganium gauge with an accuracy of $\pm 2 \mathrm{MPa}$ and the temperature of the sample was controlled inside the cell by a copper-constantan thermocouple. Measurements of dielectric permittivity were made with a HP 4192A impedance analyzer at the electric field frequency of $100 \mathrm{kHz}$. Samples were prepared in the form of pressed pellets with golden electrodes deposited on the large surfaces. The transition temperatures at various pressures were determined on heating the sample as the onset of thermal or dielectric anomaly.

The room temperature $\mathrm{x}$-ray diffraction data set was collected on a Bruker SMART CCD diffractometer with a detector to crystal distance of $60 \mathrm{~mm}$. The data set was collected with $0.3^{\circ} \omega$ slices and $40 \mathrm{~s}$ data accumulation per frame. Integration, polarization, and Lorentz corrections were performed in SAINT (Siemens Analytical Instrumentation, 1996), and absorption correction in SADABS. ${ }^{11}$ The unit cell dimensions were determined from 6571 reflections.

The high-temperature data set was collected on a KUMA-4 diffractometer. The $2 \Theta-\Theta$ scan technique was applied at a variable scan speed ranging from 0.6 to $9^{\circ} \mathrm{min}^{-1}$. The crystal was fixed in a glass capillary and heated with a hot air stream. The temperature was stabilized within $\pm 0.5 \mathrm{~K}$. The unit cell dimensions were determined from 40 automatically centered reflections. Additional information regarding data collection and reduction is given in Table I.

\section{RESULTS}

\section{A. DTA measurements}

Calorimetric measurements revealed three thermal anomalies in the $\mathrm{G}_{2} \mathrm{SnCl}_{4}$ crystals as shown in Fig. 1. The largest anomaly observed on heating the sample at $T_{m}$ $=403 \mathrm{~K}$ is related to the melting. Two others at $T_{1}$ $=354.8$ and $T_{2}=395.4 \mathrm{~K}$ correspond to the structural phase transitions. The high-temperature phase will be referred to as phase I, the intermediate phase as phase II, and the lowtemperature phase as phase III. Both the shape of the anomalies and their temperature hystereses indicate the first-order character of both transitions. The enthalpy of the phase transition between phases III and II, $\Delta H_{1}=1.41 \mathrm{~kJ} \mathrm{~mol}^{-1}$, corresponds to the entropy change $\Delta S_{1}=3.97 \mathrm{~J} \mathrm{~mol}^{-1} \mathrm{~K}^{-1}$. The magnitude of $\Delta S_{1}$ can be compared to $R \ln N_{2} / N_{3}$, where $R$ is a gas constant and $N_{2}, N_{3}$ are the numbers of configurations in phases II and III, respectively. This comparison yields $\Delta S_{1}=R \ln 1.6$ indicating that some kind of disordering can be expected in the phase II. A similar procedure applied to the anomaly at $T_{2}$ was difficult due to the overlapping of two signals arising from solid-solid and solidliquid phase transitions as seen in Fig. 1. The estimated value of the transition enthalpy $\Delta H_{2}=2.77 \mathrm{~kJ} \mathrm{~mol}^{-1}$ gives the en-

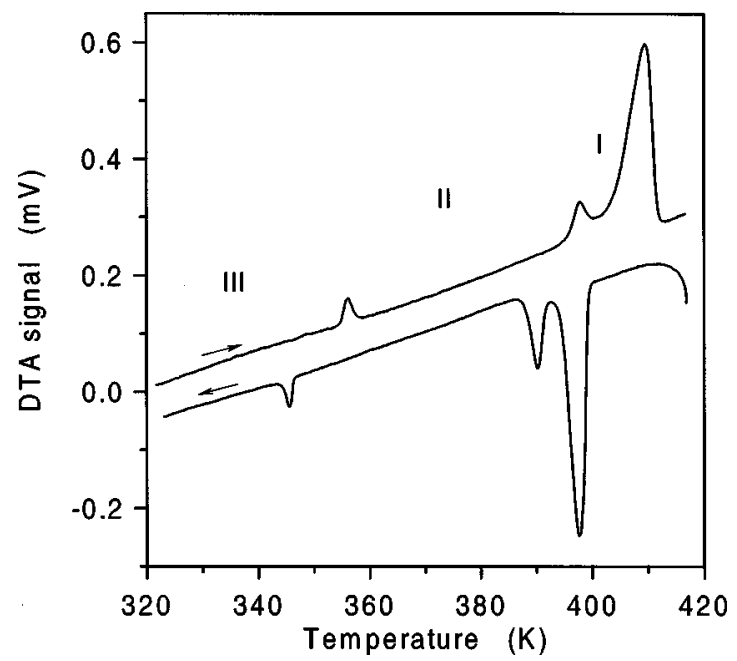

FIG. 1. DTA runs recorded on heating and cooling the $\mathrm{G}_{2} \mathrm{SnCl}_{4}$ sample at a temperature rate of $1 \mathrm{~K} \mathrm{~min}^{-1}$. The Roman numbers indicate the phases. 


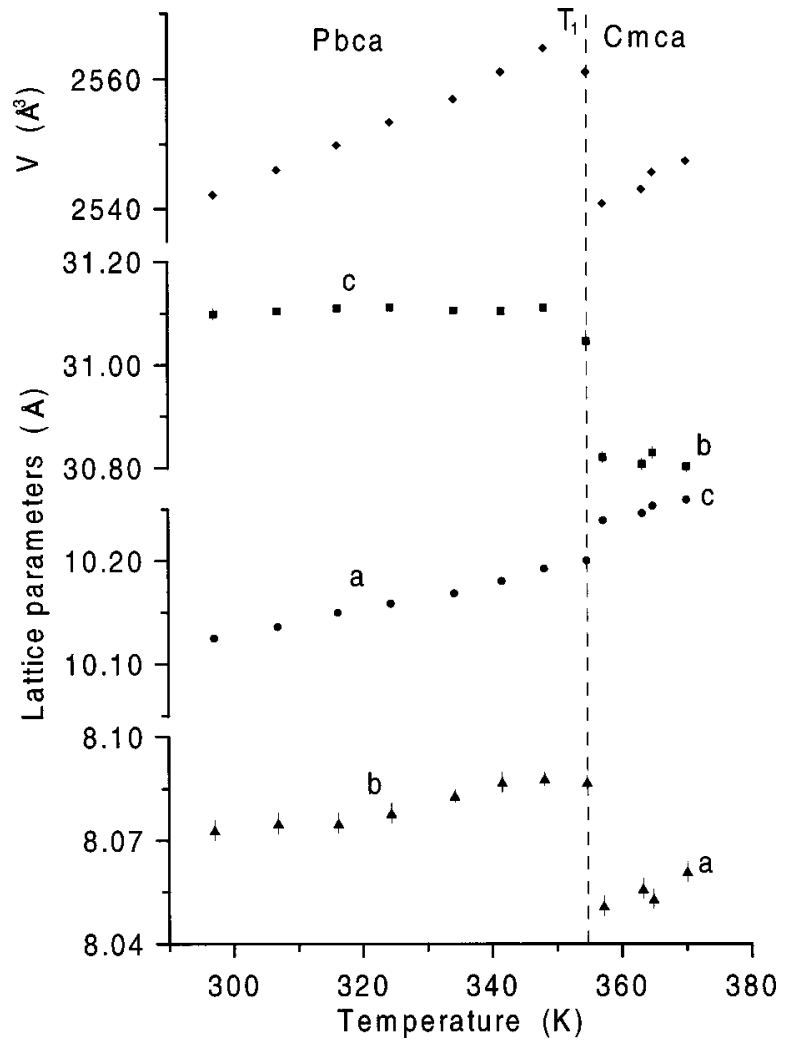

FIG. 2. Temperature dependence of lattice parameters of $\mathrm{G}_{2} \mathrm{SnCl}_{4}$ crystal in the phases II and III.

tropy change $\Delta S_{2}=7.0 \mathrm{~J} \mathrm{~mol}^{-1} \mathrm{~K}^{-1}$, which is close to $R \ln 2.3$. This large transition entropy can be explained only by the order-disorder character of the phase transition at $T_{2}$. The disordered phase I exists in a narrow temperature range between $T_{2}$ and the melting point and is difficult for study because of sublimation and a slow crystal decay.

\section{B. Temperature dependence of lattice parameters}

The unit-cell dimensions were measured in the temperature range from 290 to $370 \mathrm{~K}$, i.e., in the vicinity of the transition between phases III and II. The structural transformation at $T_{1}$ strongly affects the quality of the crystals, which often become twinned after passing to the phase II. This was observed as broadening and splitting of reflections. Several attempts have been made to obtain a single crystal in phase II of satisfactory quality. The unit cells of both phases were chosen conventionally and as a result they do not match. The unit cell of phase III can be transformed to the corresponding unit cell of phase II by $a($ III $)=c$ (II), $b$ (III) $=a(\mathrm{II})$, and $c(\mathrm{III})=b(\mathrm{II})$. As is seen in Fig. 2 the lattice parameters change abruptly at $T_{1}$, which is consistent with the first-order character of the transition, but the crystal preserves the symmetry of the orthorhombic system. The most profound changes are observed for $c$ and $b$, which contract significantly when the crystal passes through $T_{1}$. A slight elongation of $a$ does not compensate for these contractions and in a consequence a negative change of the crystal volume is observed.

\section{Crystal structure solution and refinements}

The crystal structures at 293 and $360 \mathrm{~K}$ were both solved and refined in the SHELXTL5 package. ${ }^{12}$ Due to relatively poor internal agreement factors for the $360 \mathrm{~K}$ data set several attempts were made to solve this structure in a space group lower than $\mathrm{Cmca}$. However, neither of these attempts improved the refinements. As systematic extinctions clearly pointed to $\mathrm{Cmca}$, this space group was finally chosen. The higher symmetry will also better average out spurious effects for example caused by sublimation during data collection. Both structures were solved and refined using the conventional settings. By a transformation of the $\mathrm{Cmca}$ cell to the corresponding $\mathrm{Pbca}$ cell, the former will transform into $A b m a$. Further, simply by adding an $A$ centering $+(0,1 / 2$, $1 / 2$ ), to the $P b c a$ symmetry operations one will arrive at the space group Abma. Both structures were refined with anisotropic thermal parameters for nonhydrogen atoms. Hydrogen positions in the $293 \mathrm{~K}$ structure were located in difference electron density maps. These positions were refined with a restrained N-H distance of $0.9 \AA$, while the occupancy factors and thermal parameters were kept constant. In the $360 \mathrm{~K}$ structure it was not possible to locate hydrogen positions. In both structures the second guanidinium ion $[\mathrm{C}(2), \mathrm{N}(21)$, etc.] was found disordered. The occupancy factors of the split $\mathrm{N}$ positions were initially refined, but as they did not deviate significantly from 50/50 occupancy, they were finally fixed with that ratio in both structures. More information on the refinements is found in Table I. The final atomic parameters are given in Table II and some interatomic distances and angles are shown in Table III.

\section{Crystal structure description}

The crystal structure of $\mathrm{G}_{2} \mathrm{SnCl}_{4}$ is built from $\left(\mathrm{SnCl}_{4}^{-2}\right)_{n}$ chains tied together by guanidinium ions (Figs. 3 and 4). Sn is coordinated by five chlorides in a square pyramid. Including the Sn lone pair, the coordination may be described as octahedral. Each square pyramid is connected through two neighboring corners forming infinite staggered chains. The pyramid tops are always pointing away from the chain, while the Sn lone pairs are pointing towards the chain center line. There are two crystallographically different guanidinium ions in the structure: $G(1)$, which is well ordered at both temperatures, and $G(2)$ which shows a splitting of two of the nitrogen positions in a similar way at both temperatures. The $\left(\mathrm{SnCl}_{4}^{-2}\right)_{n}$ chains and the guanidinium ions are tied together by electrostatic forces due to their charges, and in addition, by several $\mathrm{N}-\mathrm{H}-\mathrm{Cl}$ hydrogen bonds cross linking the chains into a three-dimensional structure. Analyzing the $293 \mathrm{~K}$ structure, possible $\mathrm{H}-\mathrm{Cl}$ hydrogen bonding distances are found in a relatively narrow range of $2.4-2.7 \AA$, although with large uncertainties. The corresponding $\mathrm{N}-\mathrm{Cl}$ distances are found in a likewise narrow range 3.2-3.5 $\AA$. The latter range was then applied as a criterion for hydrogen bonding in the $360 \mathrm{~K}$ structure. The proposed hydrogen bonds are given in Table IV and are indicated in the structure drawings as open bonds. On the basis of these hydrogen bonds it is seen that $G(1)$ connects the $\left(\mathrm{SnCl}_{4}^{-2}\right)_{n}$ chains on the pyramid top side forming infinite sheets perpendicular to the long axis. This arrangement, including the hydrogen bonding scheme is the same at both temperatures. $G(2)$ on the other hand connects the $\left(\mathrm{SnCl}_{4}^{-2}\right)_{n}$ chains on the lone pair side, and its orientation and hydrogen bonding scheme differs in low- and high-temperature phases as shown in Figs. 3 and 4. 
TABLE II. Fractional coordinates, isotropic temperature factor coefficients and occupancy factors for $\mathrm{G}_{2} \mathrm{SnCl}_{4}$ at (a) $293 \mathrm{~K}$ and (b) $360 \mathrm{~K}$.

\begin{tabular}{|c|c|c|c|c|c|}
\hline & $x / a$ & $y / b$ & $z / c$ & $\mathrm{U}_{\text {iso }}\left(\AA^{2}\right)$ & $g$ \\
\hline \multicolumn{6}{|c|}{ (a) $293 \mathrm{~K}$} \\
\hline $\operatorname{Sn}(1)$ & $0.82607(4)$ & $0.18957(6)$ & $0.37174(1)$ & $0.0343(1)$ & 1.0 \\
\hline $\mathrm{Cl}(1)$ & $1.0457(2)$ & $0.1907(3)$ & $0.3306(1)$ & $0.0497(4)$ & 1.0 \\
\hline $\mathrm{Cl}(2)$ & $0.9412(2)$ & $0.4380(3)$ & $0.4194(1)$ & $0.0544(5)$ & 1.0 \\
\hline $\mathrm{Cl}(3)$ & $0.7502(2)$ & $-0.0580(3)$ & $0.3097(1)$ & $0.0505(4)$ & 1.0 \\
\hline $\mathrm{Cl}(4)$ & $0.9409(2)$ & $-0.0567(3)$ & $0.4193(1)$ & $0.0512(5)$ & 1.0 \\
\hline $\mathrm{C}(1)$ & $0.4169(6)$ & $0.1929(11)$ & $0.3003(2)$ & $0.037(2)$ & 1.0 \\
\hline $\mathrm{N}(11)$ & $0.4619(6)$ & $0.1933(10)$ & $0.3406(2)$ & $0.049(2)$ & 1.0 \\
\hline $\mathrm{N}(12)$ & $0.3963(8)$ & $0.3317(10)$ & $0.2804(2)$ & $0.059(2)$ & 1.0 \\
\hline $\mathrm{N}(13)$ & $0.3936(7)$ & $0.0501(10)$ & $0.2814(2)$ & $0.053(2)$ & 1.0 \\
\hline $\mathrm{C}(2)$ & $0.2489(9)$ & $0.1671(12)$ & $0.4639(2)$ & $0.050(2)$ & 1.0 \\
\hline $\mathrm{N}(21)$ & $0.2478(7)$ & $0.2078(14)$ & $0.4224(2)$ & $0.073(2)$ & 1.0 \\
\hline $\mathrm{N}(22)$ & $0.3686(15)$ & $0.2231(23)$ & $0.4844(5)$ & $0.057(4)$ & 0.5 \\
\hline $\mathrm{N}(23)$ & $0.3290(20)$ & $0.0957(25)$ & $0.4839(6)$ & $0.071(5)$ & 0.5 \\
\hline $\mathrm{N}(24)$ & $0.1657(20)$ & $0.0917(25)$ & $0.4817(6)$ & $0.071(5)$ & 0.5 \\
\hline $\mathrm{N}(25)$ & $0.1343(17)$ & $0.2282(26)$ & $0.4850(5)$ & $0.070(7)$ & 0.5 \\
\hline $\mathrm{H}(111)$ & $0.465(8)$ & $0.088(4)$ & $0.350(3)$ & 0.08 & 1.0 \\
\hline $\mathrm{H}(112)$ & $0.487(8)$ & $0.291(5)$ & $0.352(2)$ & 0.08 & 1.0 \\
\hline $\mathrm{H}(121)$ & $0.415(8)$ & $0.423(6)$ & $0.296(2)$ & 0.08 & 1.0 \\
\hline $\mathrm{H}(122)$ & $0.390(8)$ & $0.339(11)$ & $0.252(1)$ & 0.08 & 1.0 \\
\hline $\mathrm{H}(131)$ & $0.360(7)$ & $0.054(11)$ & $0.255(1)$ & 0.08 & 1.0 \\
\hline $\mathrm{H}(132)$ & $0.4248)$ & $-0.046(6)$ & $0.292(3)$ & 0.08 & 1.0 \\
\hline $\mathrm{H}(211)$ & $0.314(6)$ & $0.152(9)$ & $0.410(2)$ & 0.08 & 1.0 \\
\hline $\mathrm{H}(212)$ & $0.170(4)$ & $0.183(12)$ & $0.410(2)$ & 0.08 & 1.0 \\
\hline $\mathrm{H}(221)$ & $0.366(9)$ & $0.147(9)$ & $0.505(2)$ & 0.08 & 1.0 \\
\hline $\mathrm{H}(222)$ & $0.412(15)$ & $0.306(15)$ & $0.471(5)$ & 0.08 & 0.5 \\
\hline $\mathrm{H}(231)$ & $0.388(13)$ & $0.026(18)$ & $0.472(5)$ & 0.08 & 0.5 \\
\hline $\mathrm{H}(241)$ & $0.129(11)$ & $0.175(10)$ & $0.497(3)$ & 0.08 & 1.0 \\
\hline $\mathrm{H}(242)$ & $0.155(18)$ & $0.044(22)$ & $0.508(3)$ & 0.08 & 0.5 \\
\hline $\mathrm{H}(251)$ & $0.079(13)$ & $0.288(19)$ & $0.469(4)$ & 0.08 & 0.5 \\
\hline \multicolumn{6}{|c|}{ (b) $360 \mathrm{~K}$} \\
\hline $\operatorname{Sn}(1)$ & 0.5000 & $0.3723(1)$ & $0.1720(2)$ & $0.050(2)$ & 0.5 \\
\hline $\mathrm{Cl}(1)$ & 0.5000 & $0.3324(4)$ & $-0.0465(6)$ & $0.074(4)$ & 0.5 \\
\hline $\mathrm{Cl}(2)$ & $0.2515(7)$ & $0.4212(2)$ & $0.0610(5)$ & $0.079(5)$ & 1.0 \\
\hline $\mathrm{Cl}(3)$ & 0.7500 & $0.3092(3)$ & 0.2500 & $0.065(4)$ & 0.5 \\
\hline $\mathrm{C}(1)$ & 0.5000 & $0.3034(21)$ & $0.5758(29)$ & $0.05(3)$ & 0.5 \\
\hline $\mathrm{N}(11)$ & 0.5000 & $0.3411(16)$ & $0.5352(31)$ & $0.06(2)$ & 0.5 \\
\hline $\mathrm{N}(12)$ & $0.6452(20)$ & $0.2796(7)$ & $0.6028(16)$ & $0.07(1)$ & 1.0 \\
\hline $\mathrm{C}(2)$ & 0.5000 & $0.4645(18)$ & $0.7500(33)$ & $0.07(3)$ & 0.5 \\
\hline $\mathrm{N}(21)$ & 0.5000 & $0.4205(14)$ & $0.7496(40)$ & $0.11(3)$ & 0.5 \\
\hline $\mathrm{N}(22)$ & $0.4438(59)$ & $0.4864(15)$ & $0.8512(25)$ & $0.10(2)$ & 0.5 \\
\hline $\mathrm{N}(23)$ & $0.5522(99)$ & $0.4900(17)$ & $0.6551(28)$ & $0.15(4)$ & 0.5 \\
\hline
\end{tabular}

During the phase transition the $G(1)$ connected double sheets slip by approximately $1 / 5$ of the original parameter $b$. The high-temperature phase is of higher symmetry as it adds an $A$ centering (referring to the $P b c a$ cell) to the original symmetry elements. The phase transition causes a change in the hydrogen bonding scheme about $G(2)$, but leaves the $G(1)$ bonding unaltered.

\section{E. $p$ - $T$ phase diagram of $\mathrm{G}_{2} \mathrm{SnCl}_{4}$}

Because of the crystal decomposition, the high-pressure measurements were limited to $380 \mathrm{~K}$, thus the pressure de-
TABLE III. Bonding distances $(\AA)$ and angles $\left(^{\circ}\right)$ in $\mathrm{G}_{2} \mathrm{SnCl}_{4}$ at 293 and $360 \mathrm{~K}$.

\begin{tabular}{|c|c|c|}
\hline & $293 \mathrm{~K}$ & $360 \mathrm{~K}$ \\
\hline $\mathrm{Sn}(1)-\mathrm{Cl}(1)$ & $2.572(2)$ & $2.555(8)$ \\
\hline $\mathrm{Sn}(1)-\mathrm{Cl}(2)$ & $2.762(2)$ & $2.750(6)[\times 2]$ \\
\hline $\mathrm{Sn}(1)-\mathrm{Cl}(3)$ & $2.891(2)$ & $2.912(6)[\times 2]$ \\
\hline $\mathrm{Sn}(1)-\mathrm{Cl}(3)$ & $2.920(2)$ & \\
\hline $\mathrm{Sn}(1)-\mathrm{Cl}(4)$ & $2.745(2)$ & \\
\hline $\mathrm{C}(1)-\mathrm{N}(11)$ & $1.338(8)$ & $1.24(8)$ \\
\hline $\mathrm{C}(1)-\mathrm{N}(12)$ & $1.302(12)$ & $1.41(4)[\times 2]$ \\
\hline $\mathrm{C}(1)-\mathrm{N}(13)$ & $1.319(11)$ & \\
\hline $\mathrm{N}(11)-\mathrm{C}(1)-\mathrm{N}(12)$ & $120.1(8)$ & $124(2)[\times 2]$ \\
\hline $\mathrm{N}(11)-\mathrm{C}(1)-\mathrm{N}(13)$ & $119.0(8)$ & \\
\hline $\mathrm{N}(12)-\mathrm{C}(1)-\mathrm{N}(13)$ & $121.9(6)$ & $112(4)$ \\
\hline $\mathrm{C}(2)-\mathrm{N}(21)$ & $1.335(10)$ & $1.36(7)$ \\
\hline $\mathrm{C}(2)-\mathrm{N}(22)$ & $1.447(18)$ & $1.32(5)[\times 2]$ \\
\hline $\mathrm{C}(2)-\mathrm{N}(23)$ & $1.177(21)$ & $1.32(6)[\times 2]$ \\
\hline $\mathrm{C}(2)-\mathrm{N}(24)$ & $1.182(22)$ & \\
\hline $\mathrm{C}(2)-\mathrm{N}(25)$ & $1.426(29)$ & \\
\hline $\mathrm{N}(21)-\mathrm{C}(2)-\mathrm{N}(22)$ & $111(1)$ & $121(4)[\times 2]$ \\
\hline $\mathrm{N}(21)-\mathrm{C}(2)-\mathrm{N}(23)$ & $130(1)$ & $126(4)[\times 2]$ \\
\hline $\mathrm{N}(21)-\mathrm{C}(2)-\mathrm{N}(24)$ & $125(1)$ & \\
\hline $\mathrm{N}(21)-\mathrm{C}(2)-\mathrm{N}(25)$ & 111(1) & \\
\hline $\mathrm{N}(22)-\mathrm{C}(2)-\mathrm{N}(23)$ & $49(1)$ & $113(5)[\times 2]$ \\
\hline $\mathrm{N}(22)-\mathrm{C}(2)-\mathrm{N}(24)$ & $124(1)$ & \\
\hline $\mathrm{N}(22)-\mathrm{C}(2)-\mathrm{N}(25)$ & $112(1)$ & \\
\hline $\mathrm{N}(23)-\mathrm{C}(2)-\mathrm{N}(24)$ & $89(1)$ & \\
\hline $\mathrm{N}(23)-\mathrm{C}(2)-\mathrm{N}(25)$ & 119(1) & \\
\hline $\mathrm{N}(24)-\mathrm{C}(2)-\mathrm{N}(25)$ & $51(1)$ & \\
\hline
\end{tabular}

pendence of $T_{2}$ was not investigated. According to the Clausius-Clapeyron relation valid for first-order phase transitions

$$
\frac{d T}{d p}=\frac{T_{0} \Delta V}{\Delta H},
$$

where $T_{0}$ is the transition temperature at ambient pressure, $\Delta V$ is the change in specific volume at $T_{0}$, and $\Delta H$ is the transition enthalpy. The transition at $T_{1}$ is associated with a reduction of the crystal volume, which implies a negative pressure coefficient $d T / d p$. Having determined $\Delta H_{1}$ from DTA measurements and $\Delta V_{1}=-1.53 \times 10^{-6} \mathrm{~m}^{3} \mathrm{~mol}^{-1}$ from x-ray dilatometric studies we calculated $d T_{1} / d p$ $=-0.385 \mathrm{~K} \mathrm{MPa}^{-1}$. This value is in good agreement with the pressure coefficient of $-0.393 \mathrm{~K} \mathrm{MPa}^{-1}$ obtained from the low-pressure $(p<100 \mathrm{MPa})$ experimental data shown in Fig. 5. The boundary between phases III and II is nonlinear and the absolute magnitude of the pressure coefficient increases with increasing pressure. As can be deduced from Eq. (1) a deviation from linearity of the $T_{1}(p)$ dependence can originate in the diminution of the transition enthalpy, in the increase of $\Delta V_{1}$, or in the changes of both these quantities induced by pressure. At elevated pressures the DTA anomaly broadens and becomes hardly detectable around $180 \mathrm{MPa}$, and finally, at higher pressures, two peaks were observed in the heating runs, as illustrated in Fig. 6. It was characteristic that, in the studied pressure range, only one 


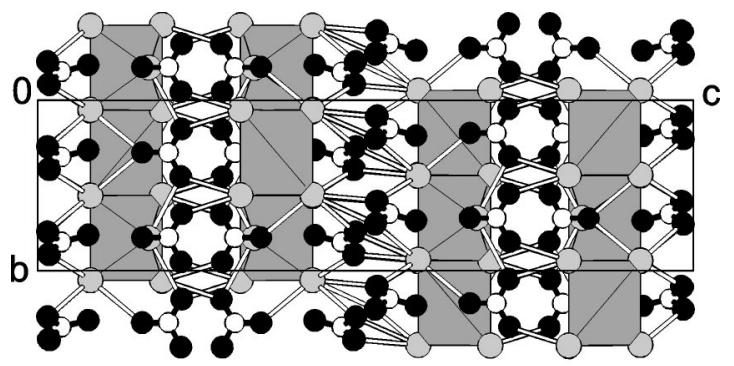

(a)

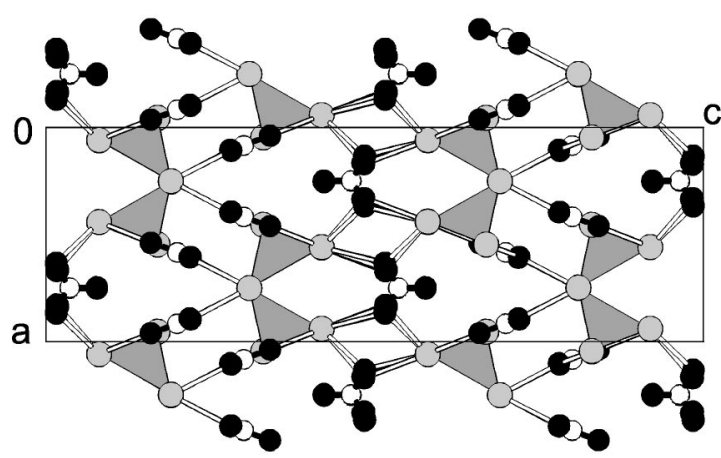

(b)

FIG. 3. The crystal structure of $\mathrm{G}_{2} \mathrm{SnCl}_{4}$ at $293 \mathrm{~K}$ viewed (a) along the $a$ axis and (b) the $b$ axis. Sn is in the square pyramids having grey chlorides at the corners. Guanidinium ions are shown with white carbon and black nitrogen atoms, the hydrogen atoms are omitted for clarity. Hydrogen bonds are drawn open.

peak was observed on cooling the sample. The occurrence of an additional thermal anomaly indicates that the crystal undergoes a pressure-induced phase transition. A new intermediate phase IV occurs between phases III and II starting from

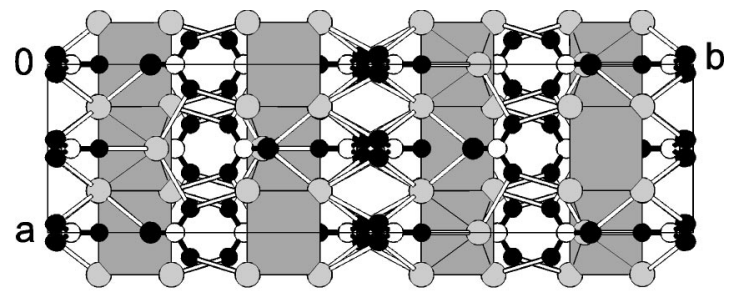

(a)

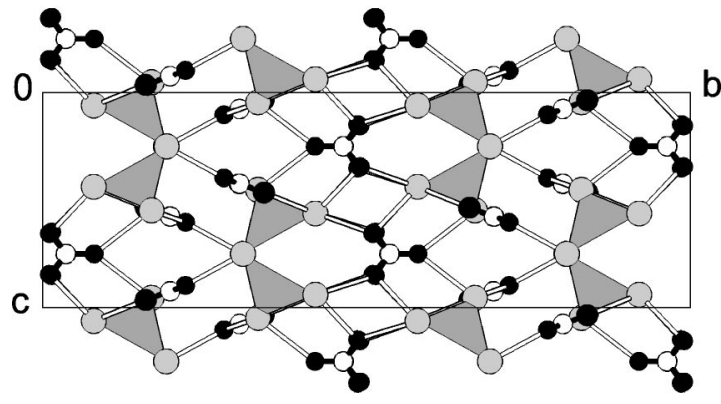

(b)

FIG. 4. The crystal structure of $\mathrm{G}_{2} \mathrm{SnCl}_{4}$ at $360 \mathrm{~K}$ viewed (a) along the $c$ axis and (b) the $a$ axis.
TABLE IV. Possible hydrogen bonds [distances in $(\AA)$, angles in $\left.\left(^{\circ}\right)\right]$ in $\mathrm{G}_{2} \mathrm{SnCl}_{4}$ at (a) $293 \mathrm{~K}$ and (b) $360 \mathrm{~K}$.

\begin{tabular}{lccc}
\hline \hline & $\mathrm{Cl}-\mathrm{H}$ & $\mathrm{Cl}-\mathrm{N}$ & $\mathrm{Cl}-\mathrm{H}-\mathrm{N}$ \\
\hline & (a) $293 \mathrm{~K}$ & & \\
$\mathrm{Cl}(1)-\mathrm{H}(121)-\mathrm{N}(12)$ & $2.46(6)$ & $3.355(8)$ & $173(6)$ \\
$\mathrm{Cl}(1)-\mathrm{H}(132)-\mathrm{N}(13)$ & $2.47(6)$ & $3.348(8)$ & $166(7)$ \\
$\mathrm{Cl}(2)-\mathrm{H}(111)-\mathrm{N}(11)$ & $2.67(7)$ & $3.360(7)$ & $134(6)$ \\
$\mathrm{Cl}(2)-\mathrm{H}(221)-\mathrm{N}(22)$ & $2.56(7)$ & $3.35(2)$ & $148(7)$ \\
$\mathrm{Cl}(2)-\mathrm{H}(231)-\mathrm{N}(23)$ & $2.49(15)$ & $3.24(2)$ & $157(13)$ \\
$\mathrm{Cl}(2)-\mathrm{H}(251)-\mathrm{N}(25)$ & $2.40(14)$ & $3.30(2)$ & $175(12)$ \\
$\mathrm{Cl}(3)-\mathrm{H}(131)-\mathrm{N}(13)$ & $2.47(5)$ & $3.311(7)$ & $156(8)$ \\
$\mathrm{Cl}(3)-\mathrm{H}(122)-\mathrm{N}(12)$ & $2.53(6)$ & $3.303(8)$ & $145(7)$ \\
$\mathrm{Cl}(4)-\mathrm{H}(112)-\mathrm{N}(11)$ & $2.55(7)$ & $3.331(7)$ & $146(6)$ \\
$\mathrm{Cl}(4)-\mathrm{H}(222)-\mathrm{N}(22)$ & $2.47(15)$ & $3.32(2)$ & $158(11)$ \\
$\mathrm{Cl}(4)-\mathrm{H}(242)-\mathrm{N}(24)$ & $2.55(7)$ & $3.23(2)$ & $148(15)$ \\
& (b) 360 K & & \\
$\mathrm{Cl}(1)-\mathrm{N}(12)$ & & $3.34(2)$ & \\
$\mathrm{Cl}(1)-\mathrm{N}(21)$ & & $3.43(4)$ & \\
$\mathrm{Cl}(2)-\mathrm{N}(11)$ & & $3.34(4)$ & \\
$\mathrm{Cl}(2)-\mathrm{N}(22)$ & & $3.33(4)$ & \\
$\mathrm{Cl}(2)-\mathrm{N}(22)$ & & $3.37(5)$ & \\
$\mathrm{Cl}(2)-\mathrm{N}(23)$ & & $3.32(6)$ & \\
$\mathrm{Cl}(2)-\mathrm{N}(23)$ & & $3.46(5)$ & \\
$\mathrm{Cl}(3)-\mathrm{N}(12)$ & & $3.24(2)$ & \\
\hline \hline
\end{tabular}

a triple point situated near $180 \mathrm{MPa}$ and $270 \mathrm{~K}$. Calorimetric results were corroborated by dielectric studies. At ambient pressure the anomaly of dielectric permittivity (see Fig. 7) shows a steplike behavior, which is typical of first-order phase transition. The transition was observed on heating and cooling the sample with a temperature hysteresis of about 8 $\mathrm{K}$. At elevated pressures the temperature hysteresis increases by almost a factor of 2 and above $180 \mathrm{MPa}$ two steplike anomalies occur in the $\varepsilon^{\prime}(T)$ dependence. In the pressure range up to $700 \mathrm{MPa}$ these two anomalies occurred in the

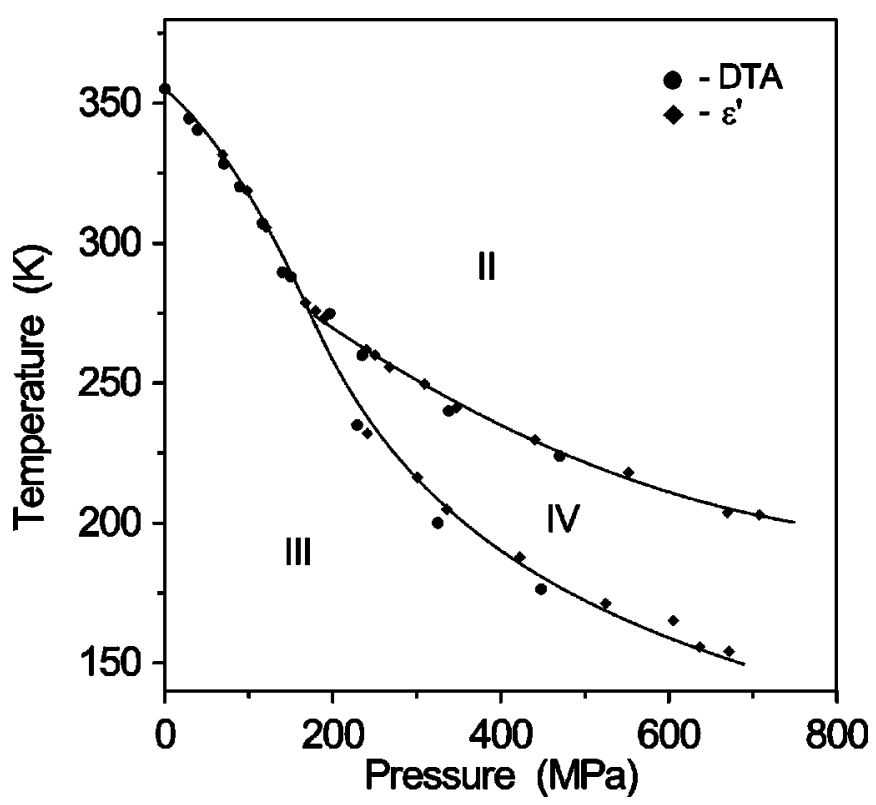

FIG. 5. $p$ - $T$ phase diagram of $\mathrm{G}_{2} \mathrm{SnCl}_{4}$. 


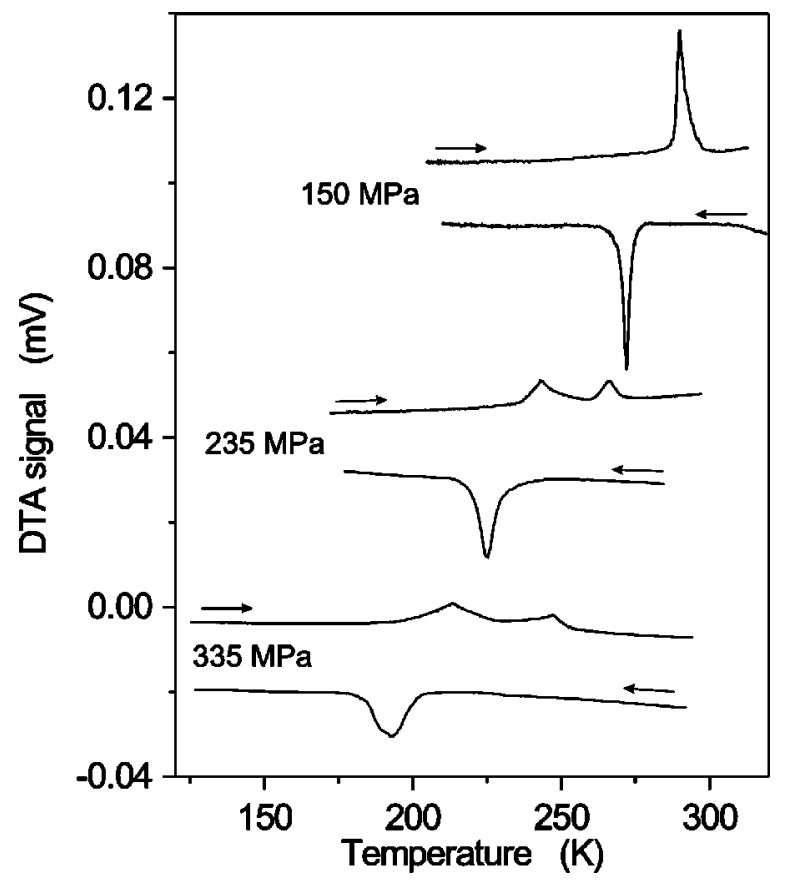

FIG. 6. DTA runs measured on heating and cooling the $\mathrm{G}_{2} \mathrm{SnCl}_{4}$ sample, as indicated by the arrows, under several pressures. The temperature was changed at a rate of $3 \mathrm{~K} \mathrm{~min}^{-1}$.

heating runs while on cooling the sample, only one jumpwise change was observed. This is due to different temperature hystereses of the transitions between phases III and IV and between phases IV and II. So, the pressure-induced phase IV can exist only when the crystal is heated from the lowtemperature phase III.

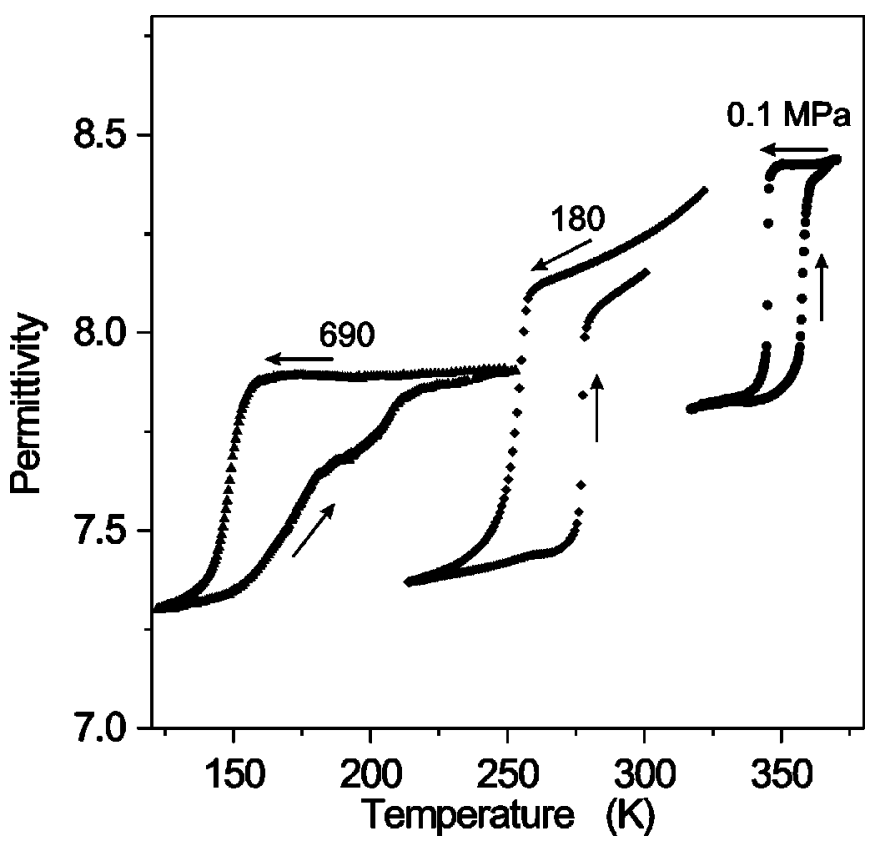

FIG. 7. Temperature dependence of the real part of dielectric constant of polycrystalline $\mathrm{G}_{2} \mathrm{SnCl}_{4}$ sample measured at ambient pressure, close to the triple point at $180 \mathrm{MPa}$ and above the triple point at $690 \mathrm{MPa}$. The arrows indicate heating/cooling runs.

\section{DISCUSSION}

The magnitude of the transition entropy indicates an order-disorder contribution to the phase transition at $T_{1}$. The total entropy gain $\Delta S_{1}=R \ln 1.6$ is lower than that expected for a two-positional disorder $(R \ln 2)$, but it should be noted that $\Delta S_{1}$ contains essentially two main components, i.e., a configurational entropy change $\Delta S_{1}^{c}$ and a volume-related entropy change $\Delta S_{1}^{v}$. Formally this can be expressed as the sum

$$
\Delta S_{1}=\Delta S_{1}^{c}+\Delta S_{1}^{v},
$$

but owing to an interdependence between the configurational and volume contributions, Eq. (2) can only be regarded as an approximation. The volume term can be estimated from the following expression: ${ }^{13}$

$$
\Delta S_{1}^{v} \approx \frac{\alpha}{\beta} \Delta V_{1},
$$

where $\alpha$ is the volume thermal expansion coefficient, $\beta$ the compressibility, and $\Delta V_{1}$ is the volume change at $T_{1}$. Taking into account that in our case $\Delta V_{1}<0$ and $\alpha>0$ (see Fig. 2), the volume-related entropy change has to be negative. Thus $\Delta S_{1}^{c}$ is higher than $\Delta S_{1}$ and actually can be close to $R \ln 2$. On the other hand, the $10 \%$ jumpwise change of the real part of dielectric constant at $T_{1}$ (see Fig. 7) indicates that the polarizability of the cation-anion system is higher in phase II, which can be connected to the dynamic disordering of $G(2)$ in two sites above $T_{1}$. This is consistent with the refinement of the crystal structure at $360 \mathrm{~K}$. The splitting of $G(2)$ was also found at room temperature, in phase III, but from the lack of any phase transition down to $80 \mathrm{~K}$ we can conclude that this is a static rather than dynamic distribution of the guanidinium cations. It is possible that $G(2)$ assumes randomly one of two sites, however, in that case it is difficult to explain the entropy change $\Delta S_{1}$. Most likely the splitting of $G(2)$ in phase III can be described as an ordering in alternating sites. This should result in a lowering of symmetry or a doubling of the unit cell. However, because the guanidinium cations are weak x-ray scatterers in comparison to more strongly scattering heavy atoms constituting the $\mathrm{G}_{2} \mathrm{SnCl}_{4}$ structure, the arrangement of $G(2)$ in alternating sites can produce very weak extra reflections which are hardly detectable.

Dynamical disordering of the $\mathrm{N}(22) \mathrm{H}_{2}$ and $\mathrm{N}(23) \mathrm{H}_{2}$ groups induces changes in the charge distribution and modifies the electrostatic interactions between the $G(2)$ cations and polyanionic chains. It is important that this disordering is coupled to the displacement of the double $G(1)$ linked sheets along $b$ and to the transformation of the hydrogen bonding pattern formed by $G(2)$ (compare Figs. 3 and 4). As a result the voids occupied by $G(2)$ cations collapse, which is clearly seen as a shortening of the unit cell parameter $c$ (Fig. 2). The complex transition mechanism is very similar to that occurring between the disordered hexagonal and ordered monoclinic phases in the crystals of $\left(\mathrm{CH}_{3}\right)_{4} \mathrm{NMnCl}_{3}$ and $\left(\mathrm{CH}_{3}\right)_{4} \mathrm{NCdCl}_{3}$ whose anionic sublattices consist of the chains of the octahedra. ${ }^{14-16}$ These similarities concern the coupling between the order-disorder process due to the organic cations and the displacive contribution coming from 
the antiparallel displacements of the polyanionic units. However, it should be stressed that in the case of $\mathrm{G}_{2} \mathrm{SnCl}_{4}$ the transformations of the polyanionic sublattice are very profound. The transition requires a simultaneous antiphase displacement of the neighboring couples of sheets by about $1.6 \AA$ which imposes a cooperative behavior of the chains of pyramids in the double sheets.

The voids occupied by $G(2)$ cations seem to be the most pressure-susceptible elements of the $\mathrm{G}_{2} \mathrm{SnCl}_{4}$ structure. At elevated pressures they are compressed, which reduces the distance between the double sheets and changes the potential determining the $G(2)$ site. This facilitates the transition, which is observed as a decrease of $T_{1}$ with increasing pressure. It is plausible that at high pressures, around $180 \mathrm{MPa}$, the coupling between the order-disorder and displacive factors weakens and finally two phase transitions occur. As illustrated in Fig. 7, for pressures above the triple point, the first dielectric anomaly observed on heating the sample is pronounced and occurs with a small temperature hysteresis while the second one is much smaller and exhibits a very large hysteresis. Moreover, the total change of the dielectric constant related to both these transitions is approximately the same as that observed at the one-step anomaly below the triple point. Taking into account, additionally, the differences in the magnitude of the thermal anomalies above the triple point, it is reasonable to assume that the transition between phases III and IV is mostly related to the disordering of the guanidinium cations while the transition between phases IV and II essentially has a displacive nature. It seems that at elevated pressures the arrangement of the polyanions in the $C m c a$ phase is stabilized by dynamical disordering of the $G(2)$ cations and their hydrogen bonds. On the other hand, when the $P b c a$ phase is heated the onset of disordering is not sufficient to provoke a rearrangement of the lowtemperature polyanionic substructure. These suggestions require, however, further studies under pressure. An interesting problem is also the broadening of the transition anomalies observed both in the calorimetric and dielectric studies at the pressures above the triple point. The triangular shape of thermal anomalies (see Fig. 6) can suggest a significant role of critical fluctuations in the crystal at elevated pressures.

\section{CONCLUSIONS}

The characteristic feature of the $\mathrm{G}_{2} \mathrm{SnCl}_{4}$ crystals is the one-dimensional polyanionic sublattice. The $\left(\mathrm{SnCl}_{4}^{-2}\right)_{n}$ chains built of square pyramids sharing corners form two kinds of voids occupied by guanidinium cations involved in two different patterns of hydrogen bonds. This differentiates the cations, their interplay with the polyanionic sublattice and their behavior at varied thermodynamic conditions. Structural peculiarities are prominent in the mechanism of the phase transitions observed at ambient and high pressures. The transition between phases III and II is markedly related to two coupled parameters arising from the displacive and order-disorder contributions. It is apparent that relatively low hydrostatic pressures induce profound changes modifying this coupling and leading to the pressure-induced phase IV. The effect of pressure is strictly related to the anisotropy of the $\mathrm{G}_{2} \mathrm{SnCl}_{4}$ structure.
${ }^{1}$ N. G. Personage and L. A. K. Staveley, Disorder in Crystals (Clarendon Press, Oxford 1978).

${ }^{2}$ R. Kind, S. Pleško, H. Arend, R. Blinc, B. Žekš, J. Seliger, B. Ložar, J. Slak, A. Levstik, C. Filipič, V. Žagar, G. Lahajnar, F. Mila, and G. Chapuis, J. Chem. Phys. 71, 2118 (1979).

${ }^{3}$ D. M. Hatch, H. T. Stokes, K. S. Aleksandrov, and S. V. Misyul, Phys. Rev. B 39, 9282 (1989).

${ }^{4}$ K. S. Aleksandrov and J. Bartolomé, J. Phys.: Condens. Matter 6, 8219 (1994).

${ }^{5}$ M. Kubicki and M. Szafrański, Acta Crystallogr., Sect. C: Cryst. Struct. Commun. 53, 1558 (1997).

${ }^{6}$ M. Kubicki and M. Szafrański, J. Mol. Struct. 446, 1 (1998).

${ }^{7}$ M. Szafrański, Thermochim. Acta 307, 177 (1997).

${ }^{8}$ M. Grottel, M. Szafrański, and Z. Pająk, Z. Naturforsch. A 52, 783 (1997).

${ }^{9}$ M. Szafrański and A. Katrusiak, Phys. Rev. B 61, 1026 (2000).

${ }^{10}$ M. Szafrański, P. Czarnecki, A. Katrusiak, and S. Habryło, Solid
State Commun. 82, 277 (1992).

${ }^{11}$ G. M. Sheldrick, SHELXTL5, An Integrated System for Solving, Refining and Displaying Crystal Structures from Diffraction Data, Siemens Analytical X-ray Instruments Inc., Madison, WI, 1995.

${ }^{12}$ G. M. Sheldrick, SADABS, University of Götingen, Germany, 1996. Siemens Analytical Instrumentation: SAINT. A program to integrate and reduce raw crystallographic area-detector data, Siemens Analytical X-ray Instruments Inc., Madison, WI, 1996.

${ }^{13}$ M. Jenau, J. Reuter, J. Ll. Tamarit, and A. Würflinger, J. Chem. Soc., Faraday Trans. 92, 1899 (1996).

${ }^{14}$ M. Couzi and Y. Mlik, J. Raman Spectrosc. 17, 117 (1986).

${ }^{15}$ M. N. Braud, M. Couzi, N. B. Chanh, C. Courseille, B. Gallois, C. Hauw, and A. Meresse, J. Phys.: Condens. Matter 2, 8209 (1990).

${ }^{16}$ V. Rodriguez, G. Aguirre-Zamalloa, M. Couzi, and T. Roisnel, J. Phys.: Condens. Matter 8, 969 (1996). 